\title{
Aids and adaptations for the elderly at home: underprovided, underused, and undermaintained
}

\author{
J GEORGE, V E BINNS, A D CLAYDEN, G P MULLEY
}

\begin{abstract}
A random sample of 140 elderly people aged over 75 was selected from the age-sex register of an urban general practice to assess the provision and use of aids and adaptations in their homes. Many of the aids that the elderly had were faulty, including half of the walking aids and $15 \%$ of hearing aids, reading spectacles, and dentures, and up to half of the aids were not used. Yet despite this underuse there were many disabled elderly people who required aids for the bath and toilet.

When screening of elderly people is carried out in general practice assessment of aids and adaptations should be included to see that they are provided where needed, are used, and are adequately maintained.
\end{abstract}

\section{Introduction}

By the age of 75 more than half of the people living at home have some type of disability.' Much can be done to help them by providing aids and adaptations. Aids are any item designed to help functional ability, ${ }^{2}$ and adaptations are aids that are fixtures in the home. These can improve the elderly person's independence and well being and may lighten the burden on them and their carers. In previous studies it was suggested that many aids and adaptations are faulty and are often ill matched to the person's needs. ${ }^{3-6}$ These

\footnotetext{
Department of Medicine for the Elderly, Cumberland Infirmary, Carlisle CA2 7HY

J GEORGE, MB, MRCP, consultant physician

Medical Statistics Unit, University of Leeds

V E BINNS, research assistant

A D CLAYDEN, PHD, senior lecturer

Department of Medicine (Elderly), St James's University Hospital, Leeds G P MULLEY, DM, FRCP, consultant physician

Correspondence to Dr George.
}

studies, however, were undertaken on selected patients with particular aids and the results therefore do not necessarily apply to elderly people in the community.

We assessed the provision, use, and condition of a wide variety of basic aids, including spectacles, dentures, hearing aids, mobility aids, and bath and toilet aids and adaptations, in a general practice population.

\section{Methods}

The study was carried out in Shipley, West Yorkshire in an urban general practice of 8000 patients, and $672(8 \cdot 4 \%)$ patients were over 75 . A random sample of 150 people over 75 was selected from the age-sex register using a table of random numbers and selecting 25 men and 25 women from each of the age groups 75-79, 80-84, and 85 and over. Each person was then visited at home by one of us (JG). The subjects were asked if they had difficulty or needed help in using the bath or toilet, and their level of mobility was ascertained.

The subjects were asked if they used accessory aids (reading spectacles, dentures, hearing aids) at least once a day. Reading spectacles (or bifocals used for reading) were inspected for broken frames and damaged or unclean lenses. Dentures were inspected for cleanliness or breakages. Hearing aids were checked to ensure that they were working, if wax was blocking the ear mould, and whether the batteries were flat.

Mobility aids were also inspected. Walking sticks were checked for length (this being considered correct if there was less than a $5 \mathrm{~cm}$ difference from the wrist crease to ground measurement) and the state of the shaft and ferrule. $^{3}$ Walking frames were assessed for general condition as well as height. Wheelchairs were examined for correctly functioning brakes and tyres. ${ }^{4}$

The subjects were asked if they regularly used bath and toilet aids and adaptations, and these were inspected for defects. The subject's ability to get in and out of the bath and on and off the toilet was assessed. Aids were provided for people who had difficulty and who requested help.

\section{Results}

When visiting was attempted six people refused to be seen, one could not be traced, and three people had recently died. Therefore 140 elderly people were assessed.

We found that many aids and adaptations were faulty (see table). Of the 16 
(13\%) subjects who had faulty spectacles, 11 had broken or dirty lenses and five had broken frames. Of the 17 subjects who had faulty dentures, 10 dentures had hard deposits on them and seven dentures were damaged. Of the four subjects who had faulty hearing aids, in two the problem was simply that the ear mould was blocked with wax. Forty three subjects had faulty walking sticks, and there were 75 faults altogether: 24 had worn ferrules; 10 had no ferrule; five had a loose ferrule; 15 had a damaged or too pliable shaft; 17 were too long and four too short. Three people had faulty walking frames: two were too long and one was too short.

Provision, use, condition, and need of aids and adaptations by 140 elderly people in general practice

\begin{tabular}{|c|c|c|c|c|}
\hline \multirow[b]{2}{*}{ Aids or adaptation } & \multicolumn{2}{|c|}{ No $(\%)$ of subjects } & \multicolumn{2}{|c|}{$\mathrm{No}(\%)$ of subjects with aids } \\
\hline & Possessing aid & Needing aid & Using regularly & Faulty aids \\
\hline Spectacles & $119(85)$ & Not assessed & $110(92)$ & $16(13)$ \\
\hline Dentures & $131(94)$ & Not assessed & $126(96)$ & $17(13)$ \\
\hline Hearing aid & $24(17)$ & Not assessed & $15(62)$ & $4(17)$ \\
\hline Walking stick & $92(66)$ & $4(3)$ & $61(66)$ & $43(47)$ \\
\hline Walking frame & $9(6)$ & 0 & $4(44)$ & $3(33)$ \\
\hline Wheelchair & $3(2)$ & $5(4)$ & $3(100)$ & $1(33)$ \\
\hline \multicolumn{5}{|l|}{ Bath: } \\
\hline Mat & $69(49)$ & $28(20)$ & $59(85)$ & 0 \\
\hline Rail & $31(22)$ & $35(25)$ & $26(84)$ & 0 \\
\hline Board & $16(11)$ & $31(22)$ & $14(87)$ & 0 \\
\hline Seat & $23(16)$ & $27(19)$ & $18(78)$ & 0 \\
\hline \multicolumn{5}{|l|}{ Toilet: } \\
\hline Raised seat & $7(5)$ & $11(8)$ & $7(100)$ & 0 \\
\hline Rail (fixed) & $13(9)$ & $15(11)$ & $12(92)$ & 0 \\
\hline Rail (free) & $2(1)$ & $1(1)$ & $2(100)$ & 0 \\
\hline
\end{tabular}

Although none of the subjects required a self propelled wheelchair, at least five would have benefited from an attendant propelled wheelchair. Spectacles and dentures were generally well used, but only 15 subjects used hearing aids regularly and walking sticks were used by only four regularly.

Only a small proportion of elderly people in the sample had bath or toilet aids and adaptations, though $83(59 \%)$ had difficulty bathing and $35(25 \%)$ required bath equipment. Similarly, $15(11 \%)$ required equipment for the toilet. Bath and toilet aids and adaptations were generally well used and in good condition.

\section{Discussion}

Providing a needed aid or adaptation can be a tremendous help to a disabled person. ${ }^{78}$ On the other hand, faulty aids are of limited use and may be dangerous, and providing equipment that is not used is wasteful and expensive. ${ }^{9}$ The results of this survey suggest that although many aids are provided, particularly to disabled elderly people, many of the aids are not used or are faulty. We found that about one in three hearing aids and walking sticks were not used and one in six hearing aids and one in two walking sticks were faulty. Despite this underuse, it seems that an insufficient number of aids to enable people to use the bath and toilet more easily were provided.

Accessory aids such as correctly fitting dentures, effective hearing aids, and spectacles are important for maintaining personal dignity. Faulty dentures and spectacles were often found, and this may reflect the difficulty that elderly people have in visiting opticians or dentists for advice and treatment. This could be overcome by the use of a voluntary transport service or by dentists and opticians visiting disabled elderly people at home. Information sheets have been posted to elderly people at home with a list of local opticians and dentists who have easily accessible premises, and these have been shown to encourage elderly people to make more use of services. ${ }^{10}$ It is disappointing, however, that the government proposes to introduce charges for dental checkups and eye testing ${ }^{11}$ as this will further discourage many elderly people from seeking advice.

Non-use of hearing aids by elderly people has been reported, ${ }^{12}$ but this might be improved by following up with counselling and advice at home.

Problems with walking sticks have been described in hospital patients. ${ }^{3}$ Walking sticks were more likely than walking frames to be used regularly. It seemed that people found manoeuvring the frame around the house difficult, and three people admitted that they used their frame for drying clothes rather than for walking. Getting about safely is crucial for elderly people, so it was disappointing to find that many of the mobility aids provided to people at home were faulty. Perhaps distributing leaflets on mobility, such as that produced by Help the Aged, ${ }^{13}$ will encourage elderly people and their medical attendants to choose walking aids more carefully and to ensure that they are adequately maintained. Surprisingly, only three subjects $(2 \%)$ owned a wheelchair, but this is comparable with a previous study. ${ }^{14}$

A striking finding was that more than half the people seen had difficulty bathing. We also found five subjects who relied on the toilet door handle to pull themselves up from the toilet. Loss of independence and difficulty in performing the personal tasks of bathing and toileting can be demoralising, and much more attention should be given in general practice to providing and assessing bath and toilet aids and adaptations. The bath and toilet aids that had been provided were generally well used and in good condition. This may be because they had been supplied only after assessment by an occupational therapist. Bath aids supplied after assessment by rehabilitation staff are more likely to be used and are less likely to be faulty. ${ }^{15}$ An occupational therapist can establish that an aid is needed and ensure that the correct aid is provided and used correctly and safely.

Our findings show that if more careful evaluation had been done before the aid was provided or if there had been a review of the equipment some of the problems could have been easily corrected. For example, health visitors could carry out the simple assessment we did during regular screening. The deficiencies that we found are probably common in other general practices. Tackling these problems with local specialists, such as opticians, dentists, audiologists, occupational therapists, or physiotherapists, would benefit many elderly people. Unfortunately, community occupational therapists and physiotherapists are often in short supply, but training district nurses, health visitors, and home helps about aids and adaptation would allow them to check and review the needs for equipment after a therapist has made the initial assessment. Follow up or review can also be done by mail or telephone.

General practitioners play an important part in identifying people who may need aids and adaptations, and it is hoped that they will work more closely with occupational therapists and make more use of Disabled Living Centres. ${ }^{16}$

We thank all the elderly people who helped us with our study; Dr J G Craig, Dr I Rutter, Dr R N Ashworth, and Dr M M Cuthbert for allowing us to study their patients; Mrs C McLaren for occupational therapy advice; and Mrs M Robson for secretarial help.

\section{References}

1 Hunt A. The elderly at home. London: HMSO, 1978:8.

Goble REA, Nichols PJR. Provision of appliances, equipment and aids. In: Rehabilitation of the severely disabled. Evaluation of a disabled living unit. London: Butterworths, 1971:68-9.

Sainsbury R, Mulley GP. Walking sticks used by the elderly. Br Med f 1982;284:1751.

4 Haworth E, Powell RH, Mulley GP. Wheelchairs used by old people. Br Med f 1983;287: 1109-10.

5 Chamberlain MA, Thornley G, Wright V. Evaluation of aids and equipment for bath and toilet. Rheumatology and Rehabilitation 1978;17:187-94.

6 Page M, Galer M, Fitzgerald J, Feeney RJ. Problems of the selection, provision and use of aids. In Bray J, Wright S, eds. The use of technology in the care of the elderly and disabled. Tools for living. London: Pinter, 1980:119-23.

Nichols PJR. Aids for daily living. The problem of the severely disabled. Applied Ergonomic 1976;73:126-32.

8 Cochrane GM. Aids in the home. Brf Hosp Med 1983;29:121-6.

9 Ward PR. Recovery and reuse of aids for disabled people: the costs and value. Health Trend $1980 ; 12: 14-5$

10 Tester S, Meredith B. Ill-informed? A study of information and support for elderly people in the inner city. London: Policy Studies Institute, 1987:61-2.

11 Anonymous. Promoting better health: government emphasises prevention and competition in primary. Pre proposals $B r$ hed $f$ 1987;295:1497-9.

12 Anonymous. Hearing problems in elderly people: implications for services [Editorial]. Lancet 1987; i:1181-2.

13 Anonymous. Mobility. London: Help the Aged, 1987.

14 Fenwick D. Wheelchairs and their users. London: HMSO, 1977.

15 Chamberlain MA, Thornley G, Stowe J, Wright V. Evaluation of aids and equipment for the bath II. A possible solution to the problem. Rheumatology and Rehabilitation 1981;20:38-43. 16 Gloag D. Aids and the environment. Br Med $\mathcal{f}$ 1985;290:220-3.

(Accepted 22 March 1988) 